\title{
The adaptation of Polish version of the Readiness for Hospital Discharge Scale (RHDS) for postpartum mothers
}

\author{
Malgorzata Nagorska, Dorota Darmochwal-Kolarz \\ Institute of Experimental and Clinical Medicine, Faculty of Medicine, University of Rzeszow, Poland
}

\begin{abstract}
Objectives: The Readiness for Hospital Discharge Scale (RHDS) for postpartum women was developed and validated in the US in 2006. The aim of the research was to analyse the psychometric properties of the Polish version of the Readiness for Hospital Discharge Scale (RHDS) for subjective assessment of the bio-psycho-physical status of women after childbirth.

Material and methods: After the preparation of the Polish-language version of the questionnaire, the study was conducted among 168 postpartum women on the day they were discharged from the hospital. For the analysis of the reliability of the questionnaire, the Cronbach Alpha test was used, where the index of values above 0.7 was assumed to mean the correct reliability of the scale.

Results: Statistical analysis using the Alpha Cronbach test for the questions presented amounted to: 0.835 , which indicates that the results are correctly aligned with one another.

Conclusions: The conducted analysis confirms that the Polish-language questionnaire in its current form has high reliability for the assessment of readiness to discharge in postpartum women and may be used in Polish conditions.
\end{abstract}

Key words: perinatal care; postpartum mothers; newborn; discharge

Ginekologia Polska 2019; 90, 7: 376-380

\section{INTRODUCTION}

Childbirth is one of the greatest events in the life of every mother and is also a great challenge for a woman, especially if it is her first child. Preparation for a new social role requires many changes in their current life. The literature refers to this as "transition to motherhood" [1, 2]. This is a special period in the life of a woman and her family, requiring the dedication of both full attention and time for a baby. It is also undoubtedly an extremely stressful situation, which often raises concerns and doubts among mothers if they will manage to cope with new obligations.

The decision about discharge is made by the medical staff, taking into account both the mother's and baby's condition. In recent years, in Poland, the stay of postpartum women has been shortened to the necessary minimum, following the criteria of the National Health Fund (insurance company), which defines and recommends the length of stay depending on the clinical situation. That is why it is extremely important to prepare mothers properly before leaving the hospital, together with taking care of the newborn and themselves during the difficult period after childbirth. Currently, there is no reliable tool in Poland for a subjective assessment of readiness to discharge of postpartum women, which is why the adaptation of the existing tool has been undertaken. The Readiness for Hospital Discharge Scale (RHDS) for postpartum mothers was developed in the USA and validated by Weiss et al. and Weiss and Piacentine [3-5].

The tool adaptation process consists of two stages: translation and evaluation of the psychometric properties of the translated scale. Its main goal is cultural adaptation and the possibility of practical scale application in Poland [6, 7].

In this paper the tool RHDS, assessing the readiness to discharge women from the hospital after the delivery, has been adapted to Polish conditions. This applies to readiness both in the physical sense (strength, energy, pain) and psychological as well as self-assessment of readiness to take care of the baby and self-care at home.

The presented study is a part of a bigger project in which adaptations were made to two other scales Quality of Dis- 
charge Teaching Scale (QDTS) and Post-Discharge Coping Difficulty Scale (PDCDS).

\section{Objectives}

The aim of the research was to analyse the psychometric properties of the Polish version of RHDS for subjective assessment of the bio-psycho-physical status of women after childbirth.

\section{MATERIAL AND METHODS Participants}

The research was carried out among postpartum women in the Department of Gynecology and Obstetrics of Clinical Provincial Hospital no 2 in Rzeszow from June to October 2017. The inclusion criteria were the delivery method and mother's aged over 18. 168 postpartum women took part in the study, and 142 fully completed questionnaires were analysed, which were included in the final analysis. Among the respondents, 51\% were urban residents, and $49 \%$ rural residents. Most of the women had higher (52\%) or secondary education (34\%). The majority of them were professionally active (70\%), married women (88\%), $92 \%$ of their husbands/partners were employed. Over half of the women (51\%) gave a vaginal birth and $49 \%$ had a Caesarean Section. For $37 \%$ of mothers, it was the first birth, and for the remaining $63 \%$ - a subsequent. Only $84 \%$ of the respondents declared exclusive breastfeeding. Almost $40 \%$ of the mothers left the hospital on the third day postpartum, $35 \%$ on the second day while $20 \%$ on the fourth day (Tab. 1 ).

\section{Instruments}

The study used a questionnaire to collect socio-demographic data created on the basis of the author's version,

\begin{tabular}{|c|c|c|c|}
\hline Question & Answer & Number $(n=142)$ & Percentage [\%] \\
\hline \multirow{2}{*}{ Place of residence } & Urban area & 72 & 51 \\
\hline & Rural area & 70 & 49 \\
\hline \multirow{7}{*}{ Education } & Primary & 1 & 1 \\
\hline & Junior high school & 2 & 1 \\
\hline & Secondary & 48 & 34 \\
\hline & Vocational & 6 & 4 \\
\hline & Higher - undergraduate & 11 & 8 \\
\hline & Higher - graduate & 58 & 41 \\
\hline & Higher - other & 16 & 11 \\
\hline \multirow{2}{*}{ Type of birth } & Vaginal birth & 73 & 51 \\
\hline & Caesarean section & 69 & 49 \\
\hline \multirow{2}{*}{ Parity } & First birth & 53 & 37 \\
\hline & Subsequent birth & 89 & 63 \\
\hline \multirow{3}{*}{ Marital state } & Married & 125 & 88 \\
\hline & Single & 1 & 1 \\
\hline & Other & 16 & 11 \\
\hline \multirow{2}{*}{ Baby feeding } & Breastfeeding & 119 & 84 \\
\hline & Baby formula milk & 23 & 16 \\
\hline \multirow{2}{*}{ Hospitalization covered } & By insurance & 140 & 99 \\
\hline & On her own & 2 & 1 \\
\hline \multirow{2}{*}{ Employment } & Working & 99 & 70 \\
\hline & Unemployed & 43 & 30 \\
\hline \multirow{3}{*}{ Husband/partner's employment } & Employed & 131 & 92 \\
\hline & Unemployed & 10 & 7 \\
\hline & I am single & 1 & 1 \\
\hline \multirow{4}{*}{ Day of discharge (since the birth) } & 2 & 49 & 35 \\
\hline & 3 & 54 & 38 \\
\hline & 4 & 29 & 20 \\
\hline & $>4$ & 9 & 7 \\
\hline
\end{tabular}


taking into account such data as: age, place of residence, education, marital status, type of insurance, occupational situation of the postpartum woman and the baby's father. The questionnaire also included questions about the obstetric situation, i.e. type of delivery, parity, way of feeding the newborn, day of discharge after birth.

\section{Readiness for Hospital Discharge Scale}

RHDS was created to assess the readiness of postpartum women to leave the hospital after birth by Weiss et al. 2006 and Weiss and Placentine (2006) [4, 5]. Before the adaptation of the tool, we obtained the consent of the author of the original version to use the scale.

RHDS consists of 23 questions, where the first question concerns the subjective assessment of the patient's readiness to leave the hospital on discharge and is recorded in the dichotomic scale (answer 1 - No, answer 2 - Yes). The remaining 22 questions reflect: personal status, knowledge, self-care ability, expected support. Each question has an 11-point scale (from 0 to 10) with a description explaining the meaning of the numerical scale (e.g. 0 not at all - 10 completely). Scores obtained from the scale range between 0 to 220. A higher score indicated greater willingness to discharge [8].

\section{The tool translation procedure}

The scale was translated into Polish by two independent translators, and then both versions were compared and one version of the translation was created. The Polish language version has been translated back into English by another translator (back translation). The prepared version was sent to the Author of the questionnaire for the final assessment of compliance with the original version. After consultation and implementing the suggested corrections, the final Polish version of RHDS was prepared. During the preparation of the Polish version of the scale, the graphic representation of the original one was also implemented.

\section{Ethical consideration}

Prior to the tests, permission for their implementation was obtained from the management of the hospital and the Bioethics Committee at the University of Rzeszow (decision number 2/4/2017).

\section{Pilot Study}

Prior to the actual research, pilot studies were carried out on a sample of 15 women in order to check the intelligibility and readability of the tools. On the basis of the collected material, several technical corrections were made in the survey.

\section{Data collection}

The survey was conducted from June to November 2017. The questionnaires were distributed among postpartum women on the day of discharge, 3 hours before going home. Two midwife volunteers, who had been previously briefed, dealt with the questionnaire. The patients were informed about the purpose of the study, its voluntary nature and anonymity, and were asked to complete it. The completion of the questionnaires took about 5 minutes.

\section{Methods of statistical analysis}

The statistical analysis was carried out with STATISTICA 13 software. Data recorded on the nominal scale (No and Yes replies) were converted to scale 1-2. The remaining scales were treated as interval scales. For each question, the obtained results were presented with descriptive statistics using the minimum and maximum values ( $\min$ and $\max$ ), quartile values (Q1, Me, Q3) and mean () and standard deviation (SD). All questions from a single sheet were analysed with Pearson's correlation, for which an interpretation of the relationship between parameters was applied in accordance with Table 2.

During the verification of all analyses, a significance coefficient $a=0.05$ was used, which allowed consideration of statistically significant variables at $p<0.05$.

The Cronbach Alpha test was used to analyse the reliability of the questionnaire. This analysis is based on the internal consistency of the responses to the questionnaire being examined. The internal consistency of the scale was measured by Cronbach Alpha. Cronbach's Alpha greater than 0.7 was adopted as satisfactory.

\section{RESULTS}

The obtained results were subjected to statistical analysis. The results obtained for the question 1 concerning the subjective assessment of readiness to discharge indicate that $96.5 \%$ of the women surveyed replied that they were ready to discharge, and only $3.5 \%$ of them gave a negative answer.

\begin{tabular}{|c|c|}
\hline $\begin{array}{l}\text { Correlation coefficient } \\
\mathbf{R}\end{array}$ & Strength of the correlation \\
\hline $0.0-0.3$ & No \\
\hline $0.3-0.4$ & Weak \\
\hline $0.4-0.7$ & Moderate \\
\hline $0.7-0.9$ & Strong \\
\hline $0.9-1.0$ & Very strong \\
\hline
\end{tabular}


From the remaining questions, the highest scores were noted for question 20 (emotional support after discharge), where the mean was 9.54 points. Other questions, which received equally high mean scores, were questions: 7 , $18,19,21-23$. In the case of two questions, a very low mean score was obtained. They relate to the stress (Q6 with mean score of 2.49) and the pain and discomfort experienced today (Q3 with mean score of 3.61). For the remaining questions, scores ranging from 7.66 to 8.80 were obtained. The results in terms of descriptive analysis are presented in Table 3.

Statistical analysis with the Alpha Cronbach test for the questions presented was: 0.835 , which indicates that the results are correctly aligned with each other. The mean correlation between the results was 0.228 . The mean result for the summed up scores of 23 questions amounted to 177.98 with a standard deviation of 19.66 points.

The current version of the questions that have the greatest negative effect on the Alpha Cronbach index are the results for the questions: 3 and 6 . The biggest positive impact related to questions from 12 to 15 . The results of the complete Alpha Cronbach analyses are presented in Table 4.

\section{CONCLUSIONS}

The conducted analysis confirms that the Polish-language questionnaire in its current form has a high reliability for the assessment of readiness to discharge in postpartum women and may be used in Polish conditions. Applying the scale in practice will assist in recognizing the readiness of women for self-care and care for the

Table 3. Descriptive analysis of RHDS results

\begin{tabular}{|c|c|c|c|c|c|c|c|}
\hline Question & Mean & $\begin{array}{l}\text { Standard deviation } \\
\text { SD }\end{array}$ & $\begin{array}{l}\text { Minimum } \\
\text { Min }\end{array}$ & $\begin{array}{l}\text { Lower } \\
\mathbf{Q}_{1}\end{array}$ & $\begin{array}{l}\text { Median } \\
\text { Me }\end{array}$ & $\begin{array}{l}\text { Upper } \\
Q_{3}\end{array}$ & $\begin{array}{l}\text { Maximum } \\
\text { Max }\end{array}$ \\
\hline Q1 & 1.04 & 0.18 & 1 & 1 & 1 & 1 & 2 \\
\hline Q2 & 8.80 & 1.74 & 1 & 8 & 10 & 10 & 10 \\
\hline Q3 & 3.61 & 2.68 & 0 & 2 & 3 & 5 & 10 \\
\hline Q4 & 7.70 & 1.96 & 1 & 7 & 8 & 9 & 10 \\
\hline Q5 & 7.86 & 1.90 & 0 & 7 & 8 & 9 & 10 \\
\hline Q6 & 2.49 & 2.99 & 0 & 0 & 1 & 3 & 10 \\
\hline Q7 & 9.07 & 1.85 & 1 & 9 & 10 & 10 & 10 \\
\hline Q8 & 8.32 & 1.90 & 3 & 7 & 9 & 10 & 10 \\
\hline Q9 & 8.41 & 1.68 & 3 & 7 & 9 & 10 & 10 \\
\hline Q10 & 8.77 & 1.38 & 4 & 8 & 9 & 10 & 10 \\
\hline Q11 & 8.75 & 1.27 & 4 & 8 & 9 & 10 & 10 \\
\hline Q12 & 7.66 & 1.99 & 0 & 7 & 8 & 9 & 10 \\
\hline Q13 & 7.94 & 2.35 & 0 & 7 & 9 & 10 & 10 \\
\hline Q14 & 7.90 & 2.19 & 0 & 7 & 8 & 10 & 10 \\
\hline Q15 & 8.32 & 2.01 & 1 & 8 & 9 & 10 & 10 \\
\hline Q16 & 7.99 & 2.07 & 0 & 7 & 8 & 10 & 10 \\
\hline Q17 & 8.56 & 1.63 & 1 & 8 & 9 & 10 & 10 \\
\hline Q18 & 9.07 & 1.35 & 3 & 9 & 10 & 10 & 10 \\
\hline Q19 & 9.13 & 1.62 & 0 & 9 & 10 & 10 & 10 \\
\hline Q20 & 9.54 & 1.11 & 4 & 10 & 10 & 10 & 10 \\
\hline Q21 & 9.19 & 1.51 & 2 & 9 & 10 & 10 & 10 \\
\hline Q22 & 9.00 & 1.86 & 1 & 9 & 10 & 10 & 10 \\
\hline Q23 & 9.12 & 1.65 & 2 & 9 & 10 & 10 & 10 \\
\hline
\end{tabular}


Table 4. Results of the Alpha Cronbach test for 23 questions from RHDS

\begin{tabular}{|l|l|l|l|}
\hline \multirow{2}{*}{ Variable } & \multicolumn{2}{|l}{$\begin{array}{l}\text { Mean }=177.98 \text { SD }=19.66 \text { Valid N:134 } \\
\text { Cronban Alfa: } \mathbf{0 . 8 3 5}\end{array}$} \\
\cline { 2 - 3 } & Square & Alpha when deleted \\
\hline Q1 & 0.469 & 0.838 \\
\hline Q2 & 0.639 & 0.829 \\
\hline Q3 & 0.357 & 0.861 \\
\hline Q4 & 0.546 & 0.830 \\
\hline Q5 & 0.640 & 0.827 \\
\hline Q6 & 0.601 & 0.882 \\
\hline Q7 & 0.677 & 0.827 \\
\hline Q8 & 0.730 & 0.823 \\
\hline Q9 & 0.731 & 0.823 \\
\hline Q10 & 0.753 & 0.820 \\
\hline Q11 & 0.759 & 0.823 \\
\hline Q12 & 0.676 & 0.817 \\
\hline Q13 & 0.743 & 0.817 \\
\hline Q14 & 0.837 & 0.813 \\
\hline Q15 & 0.812 & 0.814 \\
\hline Q16 & 0.771 & 0.817 \\
\hline Q17 & 0.492 & 0.823 \\
\hline Q18 & 0.702 & 0.820 \\
\hline Q19 & 0.400 & 0.828 \\
\hline Q20 & 0.554 & 0.833 \\
\hline Q21 & 0.773 & 0.827 \\
\hline Q22 & 0.814 & 0.829 \\
\hline Q23 & 0.859 & 0.828 \\
\hline $5 D$ & \\
\hline
\end{tabular}

SD - standard deviation newborn after discharge and will contribute to offering additional support in the bio-psycho-social dimension to patients demanding it.

\section{Funding}

Research was partially supported by the statutory fund of The Faculty of Medicine, University of Rzeszow.

\section{Acknowledgments}

The authors would like to thank Professor Marianne Weiss for permission to use the original tool and for support during this project. We would also like to thank all the women who voluntary participated in this study.

\section{REFERENCES}

1. Lothian JA. The journey of becoming a mother. J Perinat Educ. 2008; 17(4): 43-47, doi: 10.1624/105812408X364071, indexed in Pubmed: 19436533.

2. Nelson AM. Transition to motherhood. J Obstet Gynecol Neonatal Nurs. 2003; 32(4): 465-477, indexed in Pubmed: 12903696.

3. Weiss $M$, Ryan $P$, Lokken $L$, et al. Length of stay after vaginal birth: sociodemographic and readiness-for-discharge factors. Birth. 2004; 31(2): 93-101, doi: 10.1111/j.0730-7659.2004.00286.x, indexed in Pubmed: 15153128.

4. Weiss ME, Ryan P, Lokken L. Validity and reliability of the Perceived Readiness for Discharge After Birth Scale. J Obstet Gynecol Neonatal Nurs. 2006; 35(1):34-45, doi: 10.1111/j.1552-6909.2006.00020.x, indexed in Pubmed: 16466351.

5. Weiss ME, Piacentine LB. Psychometric properties of the Readiness for Hospital Discharge Scale. J Nurs Meas. 2006; 14(3): 163-180, indexed in Pubmed: 17278337.

6. Brzyski P. Aspekty metodologiczne użycia skal, jako instrumentów pomiarowych w badaniach epidemiologicznych. Prze Lek. 2012;69(12): 1287-1292.

7. Drwal R. Problemy kulturowej adaptacji kwestionariuszy osobowości. In: Ciechanowicz A. ed. Kulturowa adaptacja testów. Polskie Towarzystwo Psychologiczne,WydziałPsychologii Uniwersytetu Warszawskiego, Laboratorium TechnikDiagnostycznych im. Bohdana Zawadzkiego, Warszawa 1990:54-59.

8. Weiss M, Lokken L. Predictors and Outcomes of Postpartum Mothers' Perceptions of Readiness for Discharge after Birth. J Obstet Gynecol Neonatal Nurs. 2009; 38(4): 406-417, doi: 10.1111/j.1552-6909.2009.01040.x. 